Jara Leiva, M. J. La necesidad de un pensamiento judicial complejo en las decisiones dsobre personas indígenas privadas de libertad. Derecho y Ciencias Sociales. Noviembre 2019 - Abril 2020 N²2. Pgs 40 - 58 ISNN 1852-2971 Instituto de Cultura Jurídica y Maestría en Sociología Jurídica. FCJ y S. UNLP

\title{
La necesidad de un pensamiento judicial complejo en las decisiones sobre personas indígenas privadas de libertad
}

\author{
The need for a complex judicial thought on decisions about indigenous people deprived of \\ liberty
}

\section{María José Jara Leiva}

\section{Resumen}

En el presente artículo se ofrecerá una reflexión acerca del paradigma de la complejidad, desarrollado principalmente por Edgar Morin, en contraposición a la visión simplificadora de la realidad, propia del discurso de la modernidad y heredada por nuestros sistemas jurídicos. Se planteará la necesidad de adoptar aquel paradigma por los operadores jurídicos, encargados de aplicar las normas jurídicas a partir de la concepción que ellos tienen de la realidad, especialmente por jueces y juezas. Dicha necesidad se torna imperiosa en sociedades multiculturales, como la chilena, y en aspectos especialmente sensibles y proclives a la desatención de la diversidad cultural, como es el espacio carcelario. En concreto, se planteará que la cárcel es un espacio particularmente asimilacionista, en que las personas que pertenecen a pueblos indígenas se ven particularmente afectadas frente a una visión simplificadora de la realidad que no atienda a sus necesidades particulares durante la privación de libertad.A partir del análisis de tres sentencias judiciales ilustrativas de las decisiones en la materia, se recalcará la necesidad de construir la realidad a partir de la diversidad. Finalmente, se realizarán algunas propuestas.

Palabras clave: complejidad, simplicidad, decisión judicial, pueblos indígenas, privación de libertad.

\section{Abstract}

This article will offer a reflection on the paradigm of complexity, developed mainly by Edgar Morin, as opposed to the simplifying vision of reality, typical of the discourse of modernity and inherited by our legal systems. There will be settled the need to adopt this paradigm by legal operators, responsible for applying the legal rules on the basis of their conception of reality, especially judges. This need becomes imperative in multicultural societies, such as Chile, and in aspects especially sensitive and prone to the neglect of cultural diversity, such as prisons. In particular, it will be considered that prison is a highly assimilationist space, in which indigenous people are specially affected by a simplified vision of reality which does not meet their special needs during deprivation of liberty. The analysis of three illustrative judgements in this area will highlight the need for conceiving reality from diversity. Finally, some proposals will be made.

Key words: complexity, simplicity, judicial decisión, indigenous people, deprivation of liberty.

\footnotetext{
- Abogada de la Universidad de Chile. Máster de Estudios Avanzados por la Universidad Carlos III de Madrid. Diplomada en Derechos de los Pueblos Indígenas, Medioambiente y Procesos de diálogo e implementación de la consulta del Convenio 169, por la Facultad de Derecho de la Universidad de Chile. Fue visitante profesional en la Corte Interamericana de Derechos Humanos y pasante en Centro por la Justicia y Derecho Internacional (CEJIL). Investigadora del Observatorio contra la Violencia Institucional de Chile (OVIC). mariajose.jara.1@gmail.com
}

Recibido: 18/8/2019. Publicable: 20/12/2019 


\section{La necesidad de un pensamiento judicial complejo en las decisiones sobre personas indígenas privadas de libertad.}

María José Lara Leiva

\section{Introducción}

Los operadores jurídicosestán continuamente creando, interpretando y aplicando el Derechocon la intención de regir la realidad; y lo hacen a partir de la percepción, comprensión y conclusión que extraen sobre esta en los casos concretos y su circunscripción dentro de determinada norma jurídica. Inmersos en la tradición jurídica occidental, heredada de la época moderna, el sistema jurídico y sus operadores trabajan a partir de una visión positivista del conocimiento que implica una concepción lineal y compartimentada de la realidad yuna pretensiónde simplificación a través de la universalidad jurídica.

No obstante, esta realidad sobre la que operan y de la que son parte los sistemas jurídicos es, de hecho, compleja, ya que se encuentra plagada de otros sistemas, subsistemas, interrelaciones e interconexiones entre ellos, que la hacen ininteligible e irreductible. Ante ella, el paradigma de la simplicidad aparece como insuficiente, por provocar una abstracción que desatiende a las particularidades de la realidad y la de los sujetos y grupos situados en un tiempo y cultura determinados, y clasificar un universo que es en sí mismo diverso.

El objetivo del presente artículo es reflexionar sobre las aportaciones que conllevaría la adopción del paradigma de la complejidad en los sistemas jurídicos y en particular en las decisiones judiciales. En especial, se reflexionará acerca de la necesidad de su adopción en las decisiones de los tribunales chilenos relativas a personas indígenas privadas de libertad, dadas las especiales características tanto de la situación de las personas indígenas como de la institución del encierro. Se intentará elaborar una respuesta desde el paradigma de la complejidad para el ejercicio de derechos humanos de personas indígenas que se encuentran privadas de libertad, que tenga reconozca y tenga en cuenta su diversidad e identidad cultural, y que se construya a partir de ella.

Para ello, en primer lugar, se describirá el paradigma de la simplicidad predominante en la cientificidad moderna, tanto en el debate epistemológico como en el jurídico. Asimismo, se describirá el paradigma de la complejidad y sus aportaciones en el ámbito del conocimiento a partir de la elaboración trascendental de Edgar Morin, y su implicancia en los sistemas jurídicos a partir del desarrollo de diversos autores que, directa o indirectamente, plantean la necesidad de nuevos conceptos y concepciones adaptables a la complejidad. 
En segundo lugar, se efectuará un análisis de casos a partir de sentencias de tribunales chilenos en las que se refleja el pensamiento simplificador, que desconoce la identidad y especificidades culturales de personas pertenecientes a pueblos indígenas que se encuentran privadas de libertad, en materias sobre permisos de salida, traslado y liberación anticipada ${ }^{1}$.

En tercer lugar, se sostendrá la necesidad de la incorporación del pensamiento complejo en el sistema jurídico chileno y en las decisiones jurídicas. Para ello, se analizará algunos de los efectos particulares de la adopción de unavisión simplificadora en las decisiones relativas a la privación de libertad de personas indígenas. Se propondrá el pensamiento complejo como forma de gestionar de la complejidad existente de manera comprensiva y reconocedora de la diversidad a nivel jurídico, que plantea una relectura de qué, cómo y a partir de qué se conoce. Para terminar, se elaborarán algunas propuestas para su incorporación.

\section{De la simplicidad a la complejidad}

El discurso de la modernidad, sobre el cual se construyeron la cientificidad, el Estado y la organización económica y social deOccidente, tiene características particulares. Entre ellas, son esenciales la primacía de la razón y la abstracción, el tratamiento de lo real en base a la reducción y la disyunción, y la ocultación mutua del sujeto y el objeto de conocimiento (Morin, 1992).Su modelo de conocimiento es el positivista, con vocación descriptivista y métodos de verificación empírica y lógica, dominado por distintos paradigmas, entre los cuales se encuentra el de la simplicidad ${ }^{2}$.

En virtud de este paradigma, la ciencia intenta "eliminar todo lo que fuera individual y singular, para retener nada más que las leyes generales y las identidades simples y cerradas" (Morin, 1994: 87). Pretende poner orden al universo mediante una ley o principio, tendiendo a su simplificación y a la entrega de soluciones aisladas. Para ello, se separa lo que está ligado (disyunción), o bien se unifica lo que es diverso (reducción): "[1]a simplicidad ve a lo uno y ve a lo múltiple, pero no puede ver que lo Uno puede, al mismo tiempo, ser Múltiple” (Morin, 1994: 89). Esto tiene como consecuencia que cada ciencia y disciplina del conocimiento tiene su objeto formal y material, formando un "pensamiento parcial y unidimensional" (Morin,

\footnotetext{
${ }^{1}$ Conviene aclarar que el supuesto tratado no se refiere al del pluralismo frente al monismo jurídico, sino al tratamiento que el Derecho estatal da a las identidades étnicas y culturales diversas en un espacio con características particulares como la prisión.

${ }^{2}$ El modelo científico clásico se basó en el segundo precepto de René Descartes en su "Discurso del Método", consistente en "dividir cada una de las dificultades" en el proceso del conocimiento, a fin de examinarlas "en tanto parcelas como sea posible y que se requiera para resolverlas mejor”. (Vilar, 1997: 48-49).
} 
1994: 118). Además, prima la dialéctica entre elementos contrarios y excluyentes, y el establecimiento de una jerarquía entre ellos, lo que impide percibir las interrelaciones complejas de los elementos y sistemas.

Este paradigma penetra en el sistema jurídico de concepción moderna, que se basa sobre elementos como la abstracción, la universalidad y la racionalidad. El Derecho, al proclamara la razón como única fuente de derechos y obligaciones, sitúa entre sus principios fundadores al paradigma de la simplicidad, otorgando "valor universal [a] este sistema jurídico basado en la primacía del individuo, cuya consecuencia es la simplicidad del Derecho" (Arnaud \& Fariñas 2006: 234). Según este paradigma, el Derecho es único, inmutable y hermético, y por tanto "un sistema hermenéuticamente cerrado" (Arnaud \& Fariñas 2006: 363). Como consecuencia, se hace necesaria la simplicidad de las leyes y su no multiplicación, puesto que, al ser los derechos universales e inherentes al individuo como ser racional, bastaría su positivación en un catálogo de derechos para descubrirlos y conocerlos (Arnaud \& Fariñas, 2006), y responder a cualquier tipo de conflicto nacido de las relaciones jurídicas existentes en la sociedad. Así también, implica la existencia de prácticos del Derecho, cuya labor hermenéutica se reduce a adaptar las normas generales a los casos particulares, debiendo el juez ser solo la boca muda que pronuncia las palabras del legislador.

Esta huella reduccionista es la que es cala aún en casi la totalidad de las escuelas jurídicas y la práctica jurídico-legislativa. Todavía hoy, en la creación, ejecución, aplicación y estudio del Derecho, son muchos los que lo conciben "como un arsenal de moldes jurídicos —las normas - que se aplican sobre la realidad” (Zagrebelsky, 1995: 131), eliminando la influencia del caso concreto en la decisión.

Con el paso del tiempo, el pensamiento simplificador comienza a aparecer como inadecuado e insuficiente frente a la complejidad existente en el mundo, por conducir a la ciencia clásica a una visión determinista y atomista del universo, en detrimento de las cualidades, las unidades complejas y las interrelaciones; y producir un pensamiento reductor que genera concepciones de lo real mutiladas, que oculta las "solidaridades, interretroacciones, sistemas, organizaciones, emergencias, totalidades" (Morin, 1992: 194195).Los riesgos de la mitificación de la razón, propia del pensamiento simplificador, fueron acusados por Morin:

la razón (cerrada) se vuelve autoritaria por sí misma: al extender su universalidad potencial al universo, se apropia del universo; identifica su orden con el orden cósmico o histórico, se 
apropia de las leyes de la Naturaleza. La Razón con mayúsculas, cuando ha llegado a ser abstracta y racionalizadora, instaura en sí una guillotina ideológica y una potencialidad totalitaria (1992: 149).

En otras palabras, la racionalización, en su pretensión de encerrar el universo dentro de un sistema coherente, margina, descarta y olvida todo aquello que le contradice en la práctica (Morin, 1994: 102). Surge, así, la necesidad de un cambio de paradigma que atienda al carácter multidimensional de la realidad.

Estas insuficiencias del pensamiento simplificador se reflejan también en el discurso de los derechos humanos. Sin perjuicio de los importantes avances que ha significado el surgimiento de los derechos humanos en la época moderna, el Derecho y los derechos, concebidos tal como fueron ideados, satisfacen necesidades de siglos pasados y ajenas para las sociedades no europeas. El hecho de haberse basado en principios abstractos y absolutos los aleja de su adecuación al contexto, lo que "ha impedido que se pudiera llegar a un compromiso pragmático sobre ellos, que atendiera y diera una solución normativa a los actuales y acuciantes conflictos derivados de la pluralidad cultural y jurídica" (Fariñas, 1998: 363). No hace frente a la multiplicación de fenómenos culturales ni a la reivindicación y exigencia de reconocimiento y visibilidad de culturas que difieren de la hegemónica. Como consecuencia, el paradigma de la simplicidad "ha contribuido al ocultamiento de la pluralidad, la diversidad y la complejidad ontológica de las sociedades" (Fariñas, 1998: 366).

La teoría de la complejidad fue especialmente desarrollada por Morin, quien plantea que el conocimiento solo puede evolucionar mediante el abordaje epistemológico que ofrece esta. Fundamentalmente "se ocupa del estudio de los sistemas en los que se dan cualidades emergentes, en general, y de los sistemas adaptativos complejos, en particular" (Mancha, 2015: 267-268), por lo que como teoría ha sido abordada en campos como la cibernética, la inteligencia artificial, la teoría de los sistemas, y aplicada también a los sistemas sociales. Su finalidad es lograr un modelo explicativo del comportamiento dinámico de cualquier sistema no lineal para el cual no basten las soluciones lineales. Supone poner en entredicho el postulado positivista según el cual todo problema viene dado a priori, y cuestionar el determinismo y reduccionismo del pensamiento simplificado.

Asumir la complejidad implica admitir también la construcción cultural $-\mathrm{y}$ por tanto histórica — de la realidad. Según Morin, "la cultura es coproductora de la realidad percibida y concebida por cada cual" (1992: 24), y condiciona por tanto nuestras percepciones y normalizaciones. Por eso, dejando atrás la separación de sujeto-objeto del positivismo, para la 
teoría de la complejidad resulta necesario que el sujeto se convierta también en objeto de su propio examen, a fin de superar las ideas individuales, locales y temporales, y abrirse al intercambio con ideas extrañas que lleve a efectuar un examen crítico de las ideas endógenas (Morin, 1992), así su reflexión y relativización. Siguiendo a Foucault, "las condiciones sociales y económicas de existencia no son un velo o un obstáculo para el conocimiento sino aquello a través de lo cual se forman los sujetos el conocimiento y, en consecuencia, las relaciones de verdad" (1995: 32); es decir, hay que trabajar con el hecho de que nuestras concepciones del mundo son afectadas por condicionantes de nuestra subjetividad. Como señala Wolkmer, "es necesario enfrentar, como fenómeno físico natural perteneciente a la complejidad de la vida social y de la estructura del propio ser humano, la relatividad y la ambivalencia de las formas de "verdades"” (2006: 131).

Aplicado el pensamiento complejo al Derecho, este deja de ser entendido como un sistema hermético, impermeable a lo que pasa en el resto de los sistemas (social, político, moral, psicológico, económico, científico y cultural).Pasa a ser concebido en su calidad de sistema jurídico, objeto de una infinita interrelación con los restantes subsistemas, debiendo, por tanto, adecuarse a ellos. Así también, se reivindica, respecto de los derechos humanos, "un pensamiento y una práctica de los mismos cada vez más contextual, menos absolutista y menos idealista" (Fariñas, 1998: 364), mediante una estrategia de realización que ponga su “acento sobre lo 'alternativo', 'informal', 'local' o 'complejo"” (Arnaud \& Fariñas, 2006; 225).

La interacción entre los sistemas jurídicos y el resto de los subsistemas, incluyendo el cultural, afecta también en la creación e interpretación de las normas jurídicas, razón por la cual estas no son ni objetivas ni neutras, sino una toma de postura de quien las crea e interpreta. Por otro lado, según Zagrebelsky, el caso — que constituye un problema jurídico-, en tanto fenómeno de la realidad, también tiene que ser comprendido. De cara a la interpretación y aplicación de las normas jurídicas, "la comprensión del caso presupone que se entienda su 'sentido' y que se le dé un 'valor' a través, precisamente, de las mismas categorías de sentido y de valor de que disponga el intérprete" (1995: 136), de lo cual dependerá la búsqueda en el ordenamiento jurídico de la norma idónea para ser aplicada.

Por otro lado, si con el paradigma de la simplicidad se concebía a la ley como forma de categorizar de la realidad, con la teoría de la complejidad se produce la crisis de la generalidad de las leyes a la que hace referencia Zagrebelsky. La ley deja de aspirar a ser en 
todos y cada uno de los casos un factor de ordenación, pues a veces es una expresión del desorden "al que intenta, a lo sumo, poner remedio ex post factum" (1995: 37).

Mientras el pensamiento simplificador "resuelve los problemas simples sin problemas de pensamiento" (Morin, 1994: 118), el complejo, más que dar soluciones, constituye una estrategia para gestionarlos sobre la base de principios como el de distinción, conjunción e implicación (en contraposición a la disyunción y la reducción), siendo el "punto de partida para una acción más rica, menos mutilante” (Morin, 1994: 118). El método que propone Morin es el dialógico, que supera y relativiza la lógica deductiva-identitaria, aunque sin prescindir de ella. Este no elimina las contradicciones, las incertidumbres y la incapacidad de concebir un orden absoluto que forman parte de la complejidad de la realidad, sino que "las considera insuperables y vitales, las afronta e integra en el pensamiento" (1992: 201). Es, pues, una forma de trabajar con la complejidad del mundo ${ }^{3}$.

Uno de los desafíos del paradigma de la complejidad en nuestros sistemas jurídicos es la toma de decisión compleja, que busca la selección de una buena decisión en tanto más satisfactoria. Esta última se relaciona con un proceso de decisión ligado no a criterios de optimización, corrección o verdad (los que, en realidad, eliminan la complejidad), sino a la búsqueda de soluciones que sean satisfactorias en vistas de una serie de criterios que atiendan a la complejidad del conjunto, los que, siendo múltiples, impiden que exista una única solución correcta (Arnaud \& Fariñas, 2006).

Si nos centramos en la decisión judicial, la toma de decisión compleja puede encontrar acomodo en lo que Zagrebelsky describe como una juris prudentia, que se contrapone a la sciencia juris; la primera como racionalidad material (orientada a los contenidos), y la segunda como racionalidad formal. Mientras que el criterio que dirige la sciencia juris es la oposición cualitativa lo verdadero y lo falso, el todo y la nada (1995), el que preside a la juris prudentia, como expresión de una respuesta adaptada y adaptable a la complejidad existente, “es una progresión cualitativa que va desde lo menos a lo más apropiado, desde lo menos a lo más oportuno, desde lo menos a lo más adecuado y productivo" (1995: 123), en fin, la respuesta más apropiada frente a las expectativas legítimas. Lo anterior se debe a que el sistema jurídico no es un sistema dado y completo, sino un incesante hacerse, en el cual

${ }^{3}$ El método dialógico de Morin se puede relacionar con la denominada hermenéutica diatópica que propone Sousa como instrumento para una concepción multicultural de los derechos humanos. Su objetivo no es alcanzar la completud, puesto que aquello es inalcanzable, sino "elevar la conciencia de la incompletud a su máximo posible participando en el diálogo, como si se estuviera con un pie en una cultura y el otro en la restante". (De Sousa, 2002: 70). 
confluyen exigencias múltiples planteadas por principios que son variados y a veces contradictorios, los que "que pretenden venir realizados en contacto con la realidad viva de las experiencias sociales" (1995: 123).

\section{Decisiones de tribunales chilenos sobre personas mapuche privadas de libertad: un ejemplo de pensamiento simplificador de la realidad.}

Siguiendo la definición de De Lucas, la multiculturalidad es un hecho social. Es "la existencia, de hecho, de las manifestaciones de la diversidad, del pluralismo cultural, es decir, la presencia en una misma sociedad de grupos con diferentes códigos culturales (identidades culturales propias) como consecuencia de diferencias étnicas, lingüísticas, religiosas o nacionales" (1994: 78). En ese sentido, la sociedad chilena es multicultural—entre otras razones - por estar compuesta por diversos grupos étnicos que, junto con la sociedad chilena mestiza, conviven en el territorio del Estado ${ }^{4}$.

A pesar de ser de los pocos países latinoamericanos que no reconocen constitucionalmente a sus pueblos indígenas, tienen reconocimiento jurídico a nivel legal nueve etnias: mapuche, aymara, rapa nui, las comunidades atacameñas (en su lengua: lican antay), quechuas, collas, diaguitas, kawaskar o alacalufe, y yámana o yagán, las cuales poseen "manifestaciones étnicas y culturales propias siendo para ellos la tierra el fundamento principal de su existencia y cultura" (Ley $\mathrm{N}^{\circ} 19.235$, art. 1).

A continuación, se presentan tres sentencias en que autoridades judiciales se pronunciaron acerca del cumplimiento de la condena y las condiciones carcelarias de personas mapuche privadas de libertad, en relación con la consideración de sus formas de vida, cultura, cosmovisión y prácticas culturales. Versan sobre solicitudes de traslado a un centro penitenciario más adecuado, de acceso a libertad condicional y de permiso de salida para efectuar una ceremonia de curación. No obstante, sus prácticas pueden tener relación con otros muchos aspectos de la privación de libertad, como la atención médica intercultural y acceso a medicina tradicional, la autorización de practicar ceremonias y costumbres en el centro penitenciario, la adecuación de procedimientos de registro, la posibilidad de recibir visitas, la distribución en celdas y dormitorios adecuados, etc. ${ }^{5}$. Todas ellas, más allá de su

\footnotetext{
${ }^{4}$ En el censo del año 2017, la población en el país que se identifica como perteneciente a algún pueblo originario asciende a 2.185.729 personas, siendo los tres pueblos con mayor porcentaje el mapuche, el aymara y el diaguita. (Instituto Nacional de Estadísticas, 2008).

5 Es preciso aclarar que la mayoría de las decisiones sobre estos temas se resuelven en sede administrativa, siendo el organismo encargado de decidir sobre ellas Gendarmería de Chile, como ente encargado del cumplimiento de las condenas en prisiones.
} 
adecuación o no a Derecho, reflejan la adopción de un pensamiento simplificador frente a las circunstancias culturales.

Sentencia $N^{\circ}$ 1:En esta sentencia ${ }^{6}$ la Corte de Apelaciones de Temuco rechazóun recurso de protección interpuesto en contra del Estado, fundado en la internación definitiva de un $\mathrm{machi}^{7}$ en un centro penitenciario de la ciudad de Temuco, sin que se hayan tomado en consideración sus circunstancias particulares que exigían un deber de respeto y protección especial, puesto que dicho recinto no le permitiría vivir acorde con su cultura ${ }^{8}$; así como en la denegación del traslado solicitado a otro centro penitenciario de la ciudad de Vilcún, el que en cambio - sí contaría con medios para acceder a la naturaleza y estaría más cercano al territorio de su comunidad ${ }^{9}$, lo que le permitiría retomar contacto con el mundo espiritual de manera más equilibrada. Todo esto, alegan los recurrentes, habría vulnerado sus derechos a la vida, integridad física y psíquica; la igualdad ante la ley; y la libertad de conciencia.

La Corte de Apelaciones ${ }^{10}$ se fundó, en relación con la igualdad ante la ley, en que no se ve de qué manera esta ha sido amenazada o afectada, “considerando que los recurridos especialmente Gendarmería y el Estado de Chile se han limitado en su actuar estrictamente a las disposiciones legales que lo regulan "(Considerando $9^{\circ}$ ). En cuanto a la libertad de culto o de conciencia, la Corte estima que "tampoco se ve de qué manera se ha vulnerado este derecho ya que tal como lo reconoce los recurrentes y el recurrido Gendarmería de Chile, al condenado no se le ha privado en su actuar como machi al permitírsele, en el cumplimiento de la reglamentación el ejercicio de sus creencias, ya que incluso se le ha autorizado para efectuar las ceremonias especiales cuando asi lo ha solicitado con asistencia de su comunidad"'(Considerando 9).

Sentencia $N^{\circ} 2$ : En esta sentencia ${ }^{11}$ la Corte Suprema rechazó un recurso de apelación interpuesto frente a la negativa de conceder libertad condicional a un interno de etnia

\footnotetext{
${ }^{6}$ Corte de Apelaciones de Temuco, sentencia N 68719 de 24 de julio de 2014, en causa rol No 1655-2014.

${ }^{7}$ Autoridad política y espiritual tradicional del pueblo indígena mapuche.

${ }^{8} \mathrm{Su}$ condición de machi, así como la afectación que el encierro en el centro penitenciario de Temuco causaba a la autoridad ancestral y su comunidad, constaban en el informe pericial antropológico acompañado. Este concluía que el interno presentaba una serie de características específicas a partir de las cuales se le definía y reconocía como machi, y que la privación de libertad le impedía contar con las condiciones y elementos necesarios para mantener el equilibrio y armonía personal y de su comunidad, al no estar en contacto con las fuerzas de la naturaleza y los espíritus ancestrales, y no contar con los instrumentos simbólico-rituales ni animales.

${ }^{9}$ Se trata de un centro penitenciario agropecuario.

${ }^{10}$ Cuya decisión fue posteriormente confirmada por la Corte Suprema.

${ }^{11}$ Corte Suprema, Sala segunda (Penal), sentencia N ${ }^{\circ} 14.398-2015$, de 27 de enero de 2015 , en causa $\mathrm{N}^{\circ} 1274$ 2015.
} 
mapuche, que había sido fundado en, entre otros aspectos, no respetar el art. 10 del Convenio 169 de la OIT, el cual exige el respeto de las características económicas, sociales y culturales cuando se impongan sanciones penales a los miembros de pueblos indígenas, así como la preferencia a tipos de sanción distintos del encarcelamiento.

Respecto del reconocimiento de las características económicas, sociales y culturales a efectos de permitir el cumplimiento del resto de la pena privativa de libertad en el medio libre, la Corte estimó que se trataba de "una alegación formulada en estrados que no ha sido dotada de un contenido preciso puesto que se ha omitido explicar aquel ámbito de la cosmovisión de la etnia mapuche y de las creencias del amparado que podría verse afectado de continuar con su encarcelamiento, cuestión que estos sentenciadores tampoco advierten" (Considerando $7^{\circ}$ ).

Sentencia $N^{\circ} 3$ : En esta sentencia ${ }^{12}$ la Corte Suprema rechazó un recurso de apelación presentado en contra del Estado por el incumplimiento de tratados internacionales; específicamente por la denegación de la solicitud de salida especial de dos días y una noche, formulada por una autoridad ancestral mapuche privada de libertad, a fin de practicarse una ceremonia de saneamiento corporal y espiritual (mutreen lonkon) en su comunidad, que le permitiera reponerse de las afectaciones en su salud física y psíquica ${ }^{13}$ que le habría causado el largo período de encierro.

La Corte, si bien da por ciertas las afectaciones a su salud, estima que la interna " $h a$ tenido atención médica adecuada según lo ha manifestado el señor J. del Centro Penitenciario Femenino de Tетисо" al haber sido atendida en el centro penitenciario y derivada al Hospital Regional en diversas ocasiones (Considerando $3^{\circ}$ ). En cuanto a la salida, pese a estimar "atendible y razonable que una persona de la etnia mapuche requiera para su sanación tanto espiritual como corporal de los ritos y prácticas que a ese respecto le depara su cultura", observa que "puede existir diversos obstáculos que le impidan lograr esos cuidados. Uno de ellos ha sido la situación que su condición de condenada por delitos comunes la tiene recluida en el Centro Penitenciario Femenino de Temuco, el que se rige por

\footnotetext{
${ }^{12}$ Corte de Apelaciones de Temuco, sentencia N ${ }^{\circ}$ 10733, de 18 de mayo de 2010, en causa N $\mathrm{N}^{\circ}$ 342-2010.

${ }^{13}$ Estas afectaciones constaban en informes periciales acompañados. Al respecto, los recurrentes relatan que que para su cultura y cosmovisión, "la salud y enfermedad tienen diferentes implicancias", para lo cual requiere "siempre contacto con 'su pülli' [comunidad]; toda vez que para ser persona (che=hombre corpóreo y su ser espiritual) debe haber una relación con algún elemento de la naturaleza, el cual le proporciona la energía que le permite constituirse en ser vivo" (Vistos $\left.1^{\circ}\right)$.
} 
la ley y reglamento respectivo que no permiten (...) que la interna abandone el recinto penitenciario por dos días y una noche sin custodia "(Considerando $5^{\circ}$ ).

Estas sentencias esgrimen ciertos elementos comunes $-\mathrm{y}$, me atrevería a decir, representativos-sobre la manera en que se entiende la diversidad cultural y las características propias de los pueblos originarios, la atención que se da a sus particularidades culturales e identitarias y el rol que se entiende que recae sobre el Estado frente a ellas, cuyas respuestas reflejan una concepción simplificada de la sociedad y del sistema jurídico.

Sobre cómo se entiende la diversidad, es posible notar que en las sentencias $\mathrm{N}^{\circ} 1$ y 3 existe un prejuicio desde la cultura hegemónica sobre de qué manera se viven las ceremonias, prácticas religiosas y el cuidado de la salud de forma suficientemente adecuada con la cultura mapuche, sin acudir en primer lugar a la visión de la cultura implicada. Este nivel de lo suficiente va impuesto por las condiciones carcelarias existentes, creadas para la población penal en general; y es determinado por los ojos de los jueces, quienes disocian lo humano de lo natural, sin admitir la posibilidad de un entrecruzamiento de ambas esferas.

La sentencia $\mathrm{N}^{\circ} 2$ evidencia la visión simplificada de la sociedad, la imposición de formas culturales, y la no consideración del observante como sujeto. Los jueces, inmersos en su realidad particular socialmente construida, sin parecer ser conscientes de ello, rechazan el recurso por no lograr convencerse de la diferencia (pese a que el tratado internacional aludido no lo exige). Se puede observar, así, una relación de subordinación cultural.

Sobre el rol que se entiende recae sobre el Estado, está muy relacionado con una de las cuestiones centrales de la diferencia entre la simplicidad y la complejidad, que es qué se entiende por igualdad y cómo se actúa de forma adecuada frente a ella. En las sentencias $\mathrm{N}^{\circ} 1$ y 3 , los jueces estimaron que la igualdad es aquella en derechos, y que el Estado actúa acorde con dicho valor cuando aplica la ley al pie de la letra, de forma pareja. Así, se aprecia una pretensión de ordenar la realidad mediante la universalización, a través del principio de igualdad basado en la concepción de hombre abstracto, desatendido de su contexto, y en su sola forma de igualdad formal. Es para el destinatario general, inspirado en el hombre moderno occidental, que se encuentran diseñadas las leyes, particularmente las normas penitenciarias, y es ese criterio el que se intenta aplicar.

Los aspectos observados en las tres sentencias constituyen una forma de imperialismo cultural, según la definición entregada por Young al describir las cinco caras de la opresión, el 
que implica "la universalización de la experiencia y la cultura de un grupo dominante, y su imposición como norma” (2000: 103).Como señalan los teóricos de la complejidad respecto de la construcción social y cultural de nuestra concepción del mundo, esta autora afirma que los productos culturales dominantes serán, justamente, los que provengan de la perspectiva e interpretación de los grupos hegemónicos, que terminarán siendo impuestos a los que no lo son. Estos productos abarcan incluso la concepción que se tiene sobre otros grupos de la sociales, en la medida en que formen parte alguna categoría cultural. Lo anterior genera la paradoja para los pueblos indígenas de experimentarse como invisibles a la vez de ser señalados como diferentes (2000).

Finalmente, en la sentencia $\mathrm{N}^{\circ} 3$ se aprecia el choque de dos valores sociales: el pluralismo y la seguridad. En conflictos jurídicos enmarcados en la privación de libertad, es común apreciar esta oposición entre los valores de libertad $-\mathrm{y}$, cuando se trata de personas diversas culturalmente, pluralismo — vs. la seguridad, invocada con argumentos de vigilancia, control y eficiencia de las funciones de policía, criterios de prevención especial y la privación de libertad como regla. Ello evidencia el pensamiento reduccionista y binario de la simplicidad, que se mueve en la dialéctica de elementos concebidos como contrarios y excluyentes. Estos elementos son sometidos a una jerarquización que, en la lógica carcelaria, comúnmente cede en favor de la seguridad.

\section{Necesidad de un pensamiento complejo en decisiones sobre personas indígenas privadas de libertad en Chile.}

Los particulares efectos de la privación de libertad fueron profundamente teorizados por Foucault. Para este autor, la prisión opera como un "aparato disciplinario exhaustivo" (2009: 271) que se debe ocupar de todos los aspectos del individuo encarcelado, desde su educación hasta su actitud moral; y otorga un inmenso poder sobre quienes se hallan detenidos, mediante mecanismos como la represión y el castigo. La cárcel funciona como "la maquinaria más poderosa para imponer una nueva forma al individuo pervertido; su modo de acción es la coacción de una educación total" (2009: 271), en una especie de reformatorio integral. Además, aísla a la persona privada de libertad respecto "del mundo exterior, de todo lo que ha motivado la infracción, de las complicidades que la han facilitado" (2009: 272), de manera que la pena no debe ser solo individual, sino además individualizante.

Como señala De Lucas, el recurso a la sanción penal en sociedades multiculturales, desde el punto de vista social, "pone de manifiesto la limitación del recurso al derecho: la 
hiper simplificación que llevan a cabo los instrumentos jurídicos respecto a procesos sociales complejos" (1994: 82). Además, este autor describe los alcances colectivos que puede tener la privación de libertad, puesto que señala que la sanción penal termina convirtiéndose en, más que una mera sanción penal a individuos, una condena penal al grupo (y una exclusión social del mismo), de sus instituciones y de su cultura.

Respecto de las personas pertenecientes a pueblos originarios internadas en un centro penitenciario (generalmente en un edificio cercado y lejano a sus comunidades), un aspecto por el cual se ven especialmente afectadas, junto con el desarraigo de su comunidad, es en la relación que tienen con su territorio y recursos naturales, a los que se les asigna una significación que no es la misma que le da la cultura occidental. Para estos pueblos, el medio ambiente se posiciona "en el centro de las culturas indígenas como pilar fundamental alrededor del cual gira toda la vida política, social, económica y espiritual, y que podemos describir como interdependiente, intergeneracional, sostenible e integral, en el sentido de que afecta de manera transversal a los diferentes ámbitos de la vida de los pueblos indígenas" (Berraondo, 2006: 470). Adicionalmente, el territorio y los recursos naturales constituyen parte de su identidad cultural. Tanto así, que "[1]a negación del derecho al territorio supone prácticamente la condena a la extinción cultural y a la asimilación en las culturas mayoritarias, puesto que sin la posibilidad de ejercer los derechos territoriales, resulta muy difícil poder desarrollar derechos de autogobierno y derechos culturales arraigados en la relación con la tierra" (Berraondo, 2006: 472).

Estas especificidades culturales son atendidas por el Derecho Internacional de los Derechos Humanos. El Convenio 169 de la OIT sobre Pueblos indígenas y tribales ${ }^{14}$ establece que "[c]uando se impongan sanciones penales previstas por la legislación general a miembros de dichos pueblos deberán tenerse en cuenta sus características económicas, sociales y culturales"; y que "[d]eberá darse la preferencia a tipos de sanción distintos del encarcelamiento". Asimismo, establece que los Estados "deberán respetar la importancia especial que para las culturas y valores espirituales de los pueblos interesados reviste su relación con las tierras o territorios, o con ambos, según los casos, que ocupan o utilizan de alguna otra manera, y en particular los aspectos colectivos de esa relación" (art. 13), además

\footnotetext{
${ }^{14}$ Organización Internacional del Trabajo (1989).Convenio sobre pueblos indígenas y tribales en países independientes $\mathrm{N}^{\circ} 169$, adoptado en Ginebra, el 27 de junio de 1989, en la $76^{\circ}$ reunión CIT. Ratificado por Chile el 15 de septiembre de 2008. Los instrumentos internacionales de derechos humanos ratificados tienen en Chile valor supralegal. Constitución política de la República de Chile (1980),art. 5 inciso $2^{\circ}$.
} 
de contener otras disposiciones referentes al respeto a su cultura ${ }^{15}$. En consecuencia, los Estados deben evitar las prácticas asimilacionistas respecto de estos pueblos y sus integrantes, de manera que en cualquier intervención que los afecte, debe protegerse y fortalecerse su identidad y sentido de pertenencia, a fin de respetar y garantizar tanto sus derechos individuales como colectivos. Así, podemos decir que el Derecho Internacional de los Derechos Humanos recoge — al menos en cierta medida - la complejidad de la realidad existente, y tiene en consideración las particularidades culturales de las etnias no dominantes.

En cambio, el Derecho nacional chileno en materia penitenciaria no hace mayor referencia a las especificidades culturales en el cumplimiento de la pena. En la norma de nivel reglamentario aplicable, en una visión simplificadora de la realidad penitenciaria, se decidió ordenar la realidad mediante la homologación de los reclusos a través de la universalización del trato igual ${ }^{16}$, imponiendo solo algunas normas sobre garantía del "acceso a la cultura" (art. 6), y el fomento y respeto de actividades culturales que desarrollen los propios internos (art. 27 y 95), pero sin atender a las necesidades y vivencias diferentes que pueden tener personas con cosmovisión diversa; es decir, teniendo en cuenta la concepción del hombre abstracto, olvidando, como ya se señaló, que Chile es una sociedad multicultural.

Más allá de la simplificación normativa, el intérprete de la norma muchas veces refrenda dicha perspectiva. Una vez se decide aplicar la pena privativa de libertad a personas pertenecientes a pueblos indígenas (lo cual, de por sí, es una forma de simplificación de los procesos sociales y culturales), y según vimos en los ejemplos ofrecidos, se tiende a homologar a la población privada de libertad mediante la interpretación de forma abstracta del valor de la igualdad; priorizar la seguridad y la igualdad formal por sobre valores como el pluralismo, la libertad y la igualdad material; priorizar la normativa interna simplificadora por sobre la internacional más compleja; y, en caso de reconocerse la existencia de la diversidad, hacerlo solo desde el paradigma de la cultura dominante.

Cuando en virtud del pensamiento simplificador, que es parcial y unidimensional, se exige la adaptación de todas las personas a elementos homogeneizadores como lo es el

${ }^{15}$ El Convenio 169 ordena que, al aplicar la legislación nacional a los pueblos indígenas, “deberán tomarse debidamente en consideración sus costumbres"; y que estos "deberán tener el derecho de conservar sus costumbres e instituciones propias", siempre que no sean incompatibles con los derechos fundamentales y derechos humanos internacionalmente reconocidos. Organización Internacional del Trabajo (1989).Convenio sobre pueblos indígenas y tribales en países independientes $\mathrm{N}^{\circ} 169$, art. 8.

16 "Las normas establecidas en el presente Reglamento deben ser aplicadas imparcialmente no pudiendo existir diferencias de trato fundadas en el nacimiento, raza, opinión política, creencia religiosa, condición social o cualesquiera otras circunstancias". Decreto $N^{\circ}$ 518, Aprueba "Reglamento de Establecimientos Penitenciarios" (1998), art. 5. 
Estado, representado por la cárcel y su normativa penitenciaria, se está mutilando realidades y creando víctimas. La afectación se traduce de dos maneras: una individual y una colectiva.

Por una parte, no se atiende a que, dado que el contexto de cada persona es diferente y particular, lo que adquiere especial importancia cuando nos referimos a cosmovisiones distintas, el encierro impuesto y la posterior negación de prácticas culturales generan una afectación personal y un castigo más gravoso para unos que para otros, puesto que se ven privados de la vivencia de su espiritualidad, identidad y su cultura.

Por otro lado, provoca la marginación y ocultamiento de culturas. Los principios monocentristas e individualistas del Derecho estatal, si es que se interpretan mediante el paradigma de la simplicidad, no resultan suficientes para responder a las necesidades y reivindicaciones de movimientos indígenas, que requieren de una visión compleja de la realidad, aceptación de la diversidad, y adaptación a las particularidades culturales sobre relación con su comunidad, con el territorio. Y no solo eso, sino que, dadas las características asimilacionistas de la institución carcelaria en sí y de la normativa que la regula, se marginaliza e invisibiliza la diversidad cultural, las interacciones entre culturas, sistemas y organizaciones, $y$, en definitiva, puede producir la aculturación de ciertos grupos ${ }^{17}$.

Por todo lo anterior, resulta necesario reconocer la multiculturalidad como expresión de la complejidad existente. En la práctica de los derechos humanos, se debe dejar de concebir que estos se realizan por sujetos abstractos y ahistóricos, y adaptarlos a la realidad que de hecho es plural, mediante la toma de decisiones complejas.

En lo que toca al legislador, una de las vías para lograr lo anterior es mediante la creación de normas penitenciaras que reconozcan la complejidad y diversidad. Para De Lucas, el tratamiento de conflictos que deriven de la heterogeneidad cultural es más adecuado por vía legislativa que en la judicial, "porque así se lleva la discusión a una sede donde es posible examinar con mayor detalle y a la vez con más alcance (y con más legitimidad) el contraste entre los diferentes modelos culturales, la justificación de sus pretensiones normativas y, en su caso, el rechazo de algunas de ellas" (1994: 82). Además, tratándose de materia indígena

\footnotetext{
${ }^{17}$ Grafica lo anterior la respuesta entregada en entrevista a un preso mapuche para el informe sobre condiciones carcelarias del Instituto Nacional de Derechos Humanos: "Al menos a mí me cuesta vivir el rito acá adentro, por ser mapuche, por ser de campo, me cuesta mucho. Me cuesta porque al estar acá he olvidado muchas cosas de mi cultura, de mis raices, y no me gustaría olvidar lo que yo amo". (Instituto Nacional de Derechos Humanos, 2013: 173).
} 
deberá efectuarse previo proceso de consulta, el cual de por sí, es mayormente sensible a la complejidad que le procedimiento de creación de ley ordinario.

En cuanto a las decisiones judiciales, es necesario que los jueces y juezas dejen de percibirse a sí mismos como la boca muda que pronuncia las palabras de la ley, y que ponga la atención a las especificidades culturales en la interpretación de los hechos y de las normas. Para ello, se propone como elemento clave la interrecursividad.

Por una parte, es necesario que el juzgador recurra al Derecho Internacional de Derechos Humanos, además del Derecho interno, puesto que, al ser más complejo, permitirá alcanzar una solución más adecuada que atienda a las identidades culturales divergentes a la dominante, interrelación que ya encuentra sustento constitucional. Para ello, se debe reinventar la racionalidad jurídica, "basada no ya en la unidad de una razón jurídica universal, sino en una razón jurídica 'plural y compleja', que asuma, al menos, la existencia de una juridicidad 'policéntrica' con una multiplicidad de centros de decisión jurídica en un mismo sistema jurídico" (Fariñas, 1998: 359-360).

Esta misma recursividad debe efectuarse con otras disciplinas del saber, dejando de lado la compartimentación del conocimiento jurídico y trabajando en red, porque, “¿cómo establecer diálogos de entendimiento intercultural si está internalizado por parte de los implicados que el dialogo se hace solo con base en el discurso propio?” (Sánchez, 1998: 5). Particular importancia tiene, en lo relacionado con el mundo indígena, la antropología jurídica, entendida como un quehacer transdisciplinario que combina aportes de las ciencias jurídicas y antropológicas. Y, sin perjuicio de que no se puede alcanzar la omnicomprensión cultural, un instrumento al que se le debe dar particular valoración, por ser un apoyo trascendental para que el operador judicial perciba de mejor forma la complejidad, es el peritaje antropológico. Este permite traducir "de un lenguaje a otro, de una lógica cultural a otra, del lenguaje del sentido común y oral de la comunidad y de su lógica cultural propia al lenguaje especializado del juez y a la lógica jurídica del derecho positivo" (Ariza, Martínez, Padilla, Regalado \& Valiente, 2012: 59). Solo mediante la no parcelación del conocimiento jurídico se podrá ver de otra manera la complejidad existente.

\section{Conclusiones}

El modelo positivista de conocimiento, sobre el cual está construido el discurso de los derechos humanos de la modernidad, está basado en principios como la primacía de la razón, 
la abstracción, la universalidad y la separación entre sujeto y objeto de conocimiento. Entre sus paradigmas dominantes se encuentra el de la simplicidad, que pretende poner orden al universo mediante leyes o principios, y la entrega de soluciones puras y aisladas. Según aquel, el Derecho es único, inmutable y hermético, y requiere de prácticos que adapten las normas generales a los casos particulares.

No obstante, el paradigma de la simplicidad comienza a aparecer como inadecuado e insuficiente frente a la complejidad existente en la realidad, por conducir a una visión atomista y reductora del universo, en detrimento de las cualidades, las unidades complejas y las interrelaciones. En el ámbito de los derechos humanos, la abstracción absoluta aleja del contexto en que se realizan, sin hacer frente a la multiplicación de fenómenos sociales y culturales. El riesgo de ello es la "mutilación de la realidad", que margina y oculta a la diversidad, lo que hace necesario el surgimiento del paradigma de la complejidad.

En virtud del paradigma de la complejidad, el Derecho pasa a ser concebido como un sistema jurídico interrelacionado con el resto de los subsistemas. Se admite por ello que la realidad que observa el sujeto es fruto de una construcción creada por la interrelación de ellos, lo que afecta también al creador y al intérprete de la ley. Por eso, se entiende que ni las normas ni la percepción que se tiene sobre la realidad a la hora de aplicarlas al caso concreto son neutras, sino una toma de postura. Además, se reivindica una visión de los derechos humanos menos abstracta y más contextual, que ponga foco en lo complejo.

En instituciones disciplinadoras, aislacionistas y aculturalizantes como la prisión, cuando se entrecruza con la particularidad de la vivencia de personas indígenas, la adopción de un pensamiento complejo es particularmente importante. La relación especial con el territorio, así como los lazos con sus comunidades, hacen que sus miembros se vean doblemente afectados: como personas, por estar sometidos a un castigo más gravoso, y como pueblo y cultura, por su marginación y ocultación. Esta situación se ve materializada y perpetuada cuando, en la vivencia penitenciaria, les son negadas solicitudes relacionadas con sus prácticas culturales y espirituales mediante decisiones judiciales que reflejan un pensamiento simplificador de la realidad, como las analizadas en el presente trabajo. El choque de valores "antagónicos" que ceden en favor de criterios de seguridad, la aplicación de la mera igualdad formal, la imposición cultural, son ejemplos de este paradigma.

Por ello, resultaría más adecuado adoptar decisiones complejas en materia de condiciones penitenciarias de personas pertenecientes a pueblos indígenas. Para eso, se 
propone como factor clave la interrecursividad. En primer lugar, a estándares internacionales de derechos humanos, más receptivos de la complejidad que la ley nacional. En segundo lugar, se propone la transdisciplinariedad, especialmente mediante la antropología jurídica y el peritaje antropológico, como herramientas que le permitirán al juez o jueza comprender la complejidad del mundo indígena.

\section{Bibligrafía}

Arnaud, A.J. y Fariñas, M. J. (2006). Sistemas jurídicos: Elementos para un análisis sociológico. Madrid: Universidad Carlos III de Madrid.

Berraondo, M. (2006). Pueblos indigenas y derechos humanos. Bilbao: Instituto de Derechos Humanos, Universidad de Deusto.

De Lucas, J. (1994). "Derechos humanos, legislación positiva e interculturalidad". Documentación social, 97.

De Sousa, B. (2002). "Hacia una concepción multicultural de los derechos humanos". El otro Derecho, 28, 59-84.

Fariñas, M. J. (1998). "Los derechos humanos desde una perspectiva sociojurídica". Derechos y Libertades: revista del Instituto Bartolomé de las Casas, III (6), 355-376.

Foucault, M. (1995).La verdad y las formas jurídicas(traducido por Lynch, E.).Barcelona: Gedisa.

Foucault, M. (2009).Vigilar y castigar. Nacimiento de la prisión(traducido por Garzón del Camino, A.). México: Siglo XXI editores.

Mancha, P. (2015). "Caos, complejidad y Derecho: aportaciones de John B. Ruhl”. Anales de la Cátedra Francisco Suárez, 49, 259-280.

Morin, E. (1992).El Método IV. Las Ideas. Su hábitat, su vida, sus costumbres, su organización(traducido porSánchez, A.), Madrid: Cátedra.

Morin, E. (1994). Introducción al pensamiento complejo(traducido por: Pakman, M.). Extraído el 3 de mayo de 2019 desde http://grupal.reletran.org/wpcontent/uploads/2013/09/MorinEdgar_Introduccion-al-pensamiento-complejo.pdf

Sánchez, E. (1998). "Construcciones epistemológicas para el conocimiento de los Sistemas de derecho propio y de las justicias indígenas", América Indígena, LVIII, n 1-2.

Vilar, S. (1997).La nueva racionalidad: comprender la complejidad con métodos. Kairós.

Wolkmer, A. (2006).Introducción al pensamiento jurídico crítico. Facultad de Derecho de la Universidad Autónoma de San Luís Potosí.

Young, I. M. (2000).La justicia y las políticas de la diferencia (traducida por Álvarez, S.).Valencia: Ediciones Cátedra. 
Zagrebelsky, G. (1995).El derecho dúctil. Ley, derechos, justicia (traducidoporGascón. M.). Torino: Trotta.

\section{Otros documentos:}

Instituto Nacional de Derechos Humanos (2013).Estudio de las condiciones carcelarias en Chile. Diagnóstico del cumplimiento de los estándares internacionales de derechos humanos. Extraído el 12 de agosto de 2019 desde https://bibliotecadigital.indh.cl/bitstream/handle/123456789/639/Estudio\%20general?sequenc $\underline{\mathrm{e}=4}$

Instituto Nacional de Estadísticas (2018).Síntesis de resultados Censo 2017. Extraído el 12 de agosto de 2019 desde: https://www.censo2017.cl/descargas/home/sintesis-de-resultadoscenso2017.pdf

\section{Normativa:}

Constitución política de la República de Chile (1980).

Decreto $N^{\circ}$ 518, Aprueba "Reglamento de Establecimientos Penitenciarios". Diario Oficial de la República de Chile, Santiago, Chile, 21 de agosto de 1998.

Ley $\mathrm{N}^{\circ} 19.235$ que Establece normas sobre protección, fomento y desarrollo de los indígenas, y crea la Corporación Nacional de Desarrollo Indígena. Diario Oficial de la República de Chile, Santiago, Chile, 5 de octubre de 1993.

Organización Internacional del Trabajo (1989).Convenio sobre pueblos indígenas y tribales en países independientes $\mathrm{N}^{\circ} 169$.

\section{Jurisprudencia:}

Corte de Apelaciones de Temuco, sentencia $\mathrm{N}^{\circ} 68719$ de 24, de julio de 2014, en causa rol $\mathrm{N}^{\circ}$ $1655-2014$

Corte de Apelaciones de Temuco, sentencia $\mathrm{N}^{\circ} 10733$, de 18 de mayo de 2010, en causa $\mathrm{N}^{\circ}$ 342-2010.

Corte Suprema de Chile, Sala segunda (Penal), sentencia $N^{\circ} 14.398-2015$, de 27 de enero de 2015, en causa $\mathrm{N}^{\circ} 1274-2015$. 